\title{
Review on: Multi - Objective optimization of Composite Automobile over Drive Shaft
}

\author{
Miss. Sushmita H. Kshirsagar \\ M.E. Student \\ SVERI's College of Engineering, Pandharpur \\ e-mail: kshirsagarsushmita494@gmail.com
}

\author{
Prof. L. B. Raut \\ Assistant Professor, \\ SVERI's College of Engineering, Pandharpur \\ e-mail: lbraut@coe.sveri.ac.in
}

\author{
Prof. V. S. Jagadale \\ Assistant Professor, \\ MIT College of Railway Engineering \& Research, Barshi \\ e-mail: vishjagadale@gmail.com
}

\begin{abstract}
Composites is increasingly used in different applications in the last decade, especially in aerospace due to their high strength and lightweight characteristics. Indeed, the latest models of Airbus (A350) and Boeing (B787) have employed more than $50 \mathrm{wt} \%$ of composites, mainly Carbon Fiber Reinforced Polymers (CFRP). Yet, the increased use of CFRP has raised the environmental concerns about their end-of-life related to waste disposal, consumption of non-renewable resources for manufacturing and the need to recycle CFRP wastes. In this study, generic model is developed in order to propose an optimal management of aerospace CFRP wastes taking into account economic and environmental objectives. Initially, a life-cycle systemic approach is used to model the environmental impacts of CFRP recycling processes focusing on Global Warming Potential (GWP) following the guidelines of Life Cycle Assessment (LCA). The whole supply chain for recycling CFRP pathways is then modeled from aircraft dismantling sites to the reuse of recycled fibers in various applications. A multiobjective optimization strategy based on mathematical programming, $\varepsilon$-constraint and lexicographic methods with appropriate decision-making techniques (M-TOPSIS, PROMETHEE-GAIA) has been developed to determine CFRP waste supply chain configurations. Different scenarios have been studied in order to take account the potential of existing recycling sites in a mono-period visions as well as the deployment of new sites in a multi-period approach considering the case study of France for illustration purpose. The solutions obtained from optimization process allow developing optimal strategies for the implementation of CFRP recovery with recycled fibers (of acceptable quality) for the targeted substitution use while minimizing cost /maximizing profit for an economic criterion and minimizing an environmental impact based on GWP.
\end{abstract}

Key words: multi-objective optimization, recycling, composites materials, life cycle assessment waste management, sustainable development. $* * * * *$

\section{INTRODUCTION}

The aerospace structures like wing, fuselage, control surfaces, etc. are multi-laminated complex structural assemblies. The weight optimization of such structures is quite complex task as the design of such structures has to qualify for multiple design criteria. Thus, it is a multiobjective design optimization problem. Moreover, the estimation of design-values of different criteria for such structural problems by closed form solutions is not available. Therefore, the designer has to obtain approximate solutions. The finite element (FE) approximations using software's like ABAQUS, NASTRAN, etc. are very popular due to their ease and therefore, widely used by designers. To reach optimal solution in multi-objective optimization problem (MOOP), multiple solutions by CAE solver are required in an unguided search environment, which may be highly time taking and inefficient. On the contrast, multi-objective optimization of mathematical problems using GA is well established. Now-adays along with high speed computational facilities and structured FE meshes, numerical solutions have brought down computational time drastically. Therefore, in a step forward, if the power of evolutionary algorithms is coupled with CAE software's, then smart tailoring of laminated aerospace structural assemblies can be accomplished. The resulting structural assemblies will be highly optimized lightweight in compliance with structural design requirements. However, as these design requirements are multi-objective in nature, it is difficult to establish trade-off to have an optimal solution. Moreover, in multi-laminated structures the strength and stiffness of assembled/ co-cured structure are interdependent; hence, it is required to address such problems on a global basis. The Carbon Fibre Composites (CFC) lamina is highly anisotropic in strength and stiffness, which, in general, is used to form such tailored laminated structures.

Carbon fiber composites have been increasingly used in different applications (aerospace, automotive, industries, recreation $\cdots)$ in the last decades due to their high strength and light weight characteristics. In aerospace, they have progressively replaced metals and alloys in order to reduce fuel consumption. Composites have been used originally in military 
aircraft and have then been adopted progressively in civil airplane from secondary part to primary structure in the latest models of Boeing and Airbus, e.g. B787 with 50 wt $\%$ in composite, A350 with 53 wt\% in composite (Figure 1). These two models have marked the revolution of CFRP composite utilization in airframe with CFRP fuselage. Adopted since 1970s, CFRP is increasingly used in structural applications of aircraft to replace more conventional materials (steel, aluminium, alloys $\cdots$ ) in order to design lighter products due to their low density and high performance of chemical and physical properties and become the major composite in recent models among the other composites (GFRP, GLARE, Carbon/Carbon Composite $\cdots)$. This material is constituted of two main components: carbon fiber and polymer matrix. In aerospace applications, carbon fiber exhibits the high mechanical properties and polymer matrix is principally thermoset.

\section{Objectives:}

a) To Multi-objective optimization of composite material using grey relation analysis to Increases the fundamental Natural Frequency and torsion Strength.

b) To develop Statistical model for failure Analysis of Composite Material.

c) To parametric study for deciding design variable and constraint.

d) To develop and Manufactured proposed composite drive shaft.

e) To Perform Experimental Analysis of Automobile over drive Shaft.

Use of advanced composites has resulted inremarkable achievements in many fields including aviation, marine and automobile engineering, medicine, prostheticsandsports, in terms of improved fatigue and corrosion resistances, high specific modulus and specific strength and reduction in energy requirements owing to minimization in weight. The goal of this work is to replacethe conventional steel driveshaft of automobiles with anappropriate composite driveshaft. The conventional driveshafts are made in two pieces for reducing the bending natural frequency, whereas the composite shafts can be made as single-piece shafts, thus reducing the overall weight. Carbon/EpoxyandKevlar/Epoxy composites were designedand analysed for their appropriatenessin terms of torsional strength, bending natural frequency and torsional bucklingby comparing them with the conventional steel driveshaftunder the same grounds of design constraints and the best-suited composite was recommended. Light has been thrown upon the aspects like number of plies, mass saving and ply distribution.

Use of fiber-reinforced laminated composites has proved itself as a valuable option in the manufacturing of risers, particularly for deepwater applications, a scenario where its lightweight related properties and good fatigue resistance are most needed. In addition, its use allows these structures to be tailored to meet specific manufacturing, safety, and stability criteria. This paper proposes an optimization model to composite risers in a freehanging catenaries configuration that considers multiple load cases and two objective functions. The optimization is carried out using a modified version of the Non dominated Sorting Genetic Algorithm II (NSGA-II). The riser structural analysis is performed by an inextensible cable model that accounts for the vertical static loads, floater offset and current loads in a fast and efficient way. The proposed algorithm is validated using a benchmark problem and applied to obtain the Pareto Front of a composite riser.

The present study aims to minimize the weight of multilaminate aerospace structures by a classical Genetic Algorithm (GA) interfaced with a CAE solver. The structural weight reduction is a multi objective optimization problem subjected to fulfilling of strength and stiffness design requirements as well. The desired fitness function connects to the multiobjective design requirements to form a single-objective function by using carefully chosen scaling factors and a weight vector to get a near optimal solution. The scaling factors is normalize and the weight vector prioritizes the objective functions. The weight vector selection was based on posteriori articulation, after accessing a series of Pareto fronts by $3 \mathrm{D}$ hull plot of strength, stiffness and assembly weight data points. During the optimization, the algorithm accomplish intelligent laminate selection based on a static strength and alters the ply orientations and thickness of laminae for faster convergence. The study further brings out the influence of mutation percentage on the convergence. The procedure of optimization on transport aircraft wing torsion box has showed $29 \%$ reduction in weight compared to an initial quasi-isotropic laminated structure and $54 \%$ with respect to the metallic structure.

Yiyo Kuo, TahoYang and Guan-Wei Huang explained how Simulation modeling is a widely accepted tool in system design and analysis, particularly when the system or environment has stochastic and nonlinear behavior. After all, it does not provide a method for optimization. In general, the problems consist of more than one response, which are often in conflict with each other. This article focus on a grey-based Taguchi method to solve the multi-response simulation problem. The grey-based Taguchi method is based on the optimizing procedure of the Taguchi method, and adopts grey relational analysis (GRA) to transfer multi-response problems into single-response problems. A practical case study from an integrated-circuit packaging company clarify that differences in performance of the proposed grey-based Taguchi method and other methods found in the literature were not significant. The grey-based Taguchi method thus provides a new option when solving a multi-response simulation-optimization problem. 
Composites has been increasingly applied in different applications in the last decade, especially in aerospace due to their high strength and lightweight characteristics. Indeed, the latest models of Airbus (A350) and Boeing (B787) have employed more than $50 \mathrm{wt} \%$ of composites, mainly Carbon Fiber Reinforced Polymers (CFRP). Yet, the increased use of CFRP has raised the environmental concerns about their endof-life related to waste disposal, consumption of non-renewable resources for manufacturing and the need to recycle CFRP wastes. In this study, a generic model is first developed in order to propose an optimal management of aerospace CFRP wastes taking into account economic and environmental objectives. Firstly, a life-cycle systemic approach is preferred firstly to model the environmental impacts of CFRP recycling processes focusing on Global Warming Potential (GWP) following the guidelines of Life Cycle Assessment (LCA). The whole supply chain for recycling CFRP pathways is then modeled from aircraft dismantling sites to the reuse of recycled fibers in various applications. A multiobjective optimization strategy based on mathematical programming, $\varepsilon$-constraint and lexicographic methods with appropriate decision-making techniques (M-TOPSIS, PROMETHEE-GAIA) has been developed to determine CFRP waste supply chain configurations. Various scenarios have been studied in order to take account the potential of existing recycling sites in a monoperiod visions as well as the deployment of new sites in a multi-period approach considering the case study of France for illustration purpose. The solutions obtained from optimization process allow developing optimal strategies for the implementation of CFRP recovery with recycled fibers (of acceptable quality) for the targeted substitution use while minimizing cost /maximizing profit for an economic criterion and minimizing an environmental impact based on GWP. se of advanced composites resulted in remarkable achievements in many fields including aviation ,marine and automobile engineering, medicine, prosthetics and sports, in terms of improved fatigue and high specific strength, corrosion resistances and specific modulus and reduction in energy requirements owing to reduction in weight. The objective of this work is to replace the conventional steel driveshaft of automobiles with an appropriate composite driveshaft. The conventional drive shafts are made in two pieces for reducing the bending natural frequency, whereas the composite shafts can be made as single-piece shafts, thus reducing the overall weight. Carbon/Epoxy and Kevlar/Epoxy composites was designed and analyzed for their appropriateness in terms of torsional strength, bending natural frequency and torsional buckling by comparing them with the conventional steel driveshaft under the same grounds of design constraints and the best-suited composite was recommended. Light has been thrown upon the aspects like number of plies, mass saving, and ply distribution
The Fundamental concept of our project is to reduce the weight of automotive drive shaft with the utilization of composite material. Composite materials has been used in automotive components because of their properties such as low weight, high specific stiffness, corrosion free, ability to produce complex shapes and high impact energy absorption and high specific strength etc. As the automotive drive shaft is a very important component of vehicle. The modeling of the drive shaft assembly was carriedout using CATIA software. A shaft has to be designed to meet the stringent design requirements for automotives. In automobiles the drive shaft is used for transmission of motion from the engine to the differential. An automotive propeller shaft, or drive shaft, transmits power from the engine to differential gears of rear wheel-driving vehicle. In current work an attempt has been to determine deflection, stresses under subjected loads \& natural frequencies using FEA.

The Roadway vehicles like cars, buses, trucks and land movers having many mechanical parts in common like Engine parts, Propeller shafts, Gearbox, Brakes, Clutches, Wheels, etc., To make the vehicle fuel efficient which in result make the transportation economical, the weight of that vehicle should be reduced. Since the composite materials are light weight with more strength \& stiffness, inclusion of composite materials to conventional steel materials used in auto parts will reduce the weight and improve the mechanical properties of those components. This project deals with propeller shaft of MARUTHI OMNI to design the shaft for its minimum dimensions to satisfy current problem specification and then replace conventional steel material with composite material. The design of the propeller shaft is first theoretically designed for steel, Carbon/Epoxy and Glass/Epoxy composite material for its safe dimensions. Then they can be created as a part model for respective dimensions in NX 8.5 software. After modeling, Torsional buckling analysis and Modal analysis can be carried out in the propeller shafts using NX NASTRAN to check whether theoretical calculations and analytical results are similar. Then obtained results are compared among those three materials and Carbon/Epoxy composite material is selected as suitable replacement material for conventional steel material in terms of several mechanical properties.

\section{REFERENCES}

[1] Shrivastava S, Mohite P. Design and optimization of a composite canard control surface of an advanced fighter aircraft under static loading. Curved Layered Struct 2015;2(1):91-105. http://dx.doi.org/10.1515/cls-2015-0006.

[2] Deb K. Optimization for engineering design: algorithms and examples. India: Prentice-Hall of India9788120309432; 2004.

[3] Miettinen K, Ruiz F, Wierzbicki A. Introduction to Multiobjective Optimization: Interactive Approaches. In: Branke J, Deb K, Miettinen K, Slowinski R. (Eds.,) Multiobjective 
Optimization. Lecture Notes in Computer Science. Berlin, Heidelberg: Springer; 2008. ISBN 978-3-540-88907-6.

[4] Almeida F, Awruch A. Design optimization of composite laminated structures using genetic algorithms and finite element analysis. Compos

Struct $2009 ; 88(3): 443-54$ http://dx.doi.org/10.1016/j.compstruct.2008.05.004.

[5] Karakaya S, Soykasap O. Buckling optimization of laminated composite plates using genetic algorithm and generalized pattern search algorithm. Struct Multidiscip Optim 2009;39(5):477-86. http://dx.doi.org/10.1007/s00158-008-0344-2.

[6] Diaconu C, Sekine H. Layup optimization for buckling of laminated composite shells with restricted layer angles. AIAA 2004;42(10):2153-63. http://dx.doi.org/10. 2514/1.931.

[7] Ijsselmuiden S, Abdalla M, Gürdal Z. Optimization of variablestiffness panels for maximum buckling load using lamination parameters.

AIAA

2010;48(1):134-43. 